\title{
As doze badaladas ou corpos em construção: uma análise da representação fugidia de Marieta de Sérgio Sant'Anna
}

\author{
Ludimila Moreira Menezes ${ }^{1}$
}

RESUMO: Este artigo se propõe a percorrer e discutir as estratégias discursivas usadas para a construção da identidade fugidia de Marieta em Marieta e Ferdinando escrito por Sérgio Sant'Anna. O trabalho investiga as relações entre as performances de gênero e o projeto do narrador de representar o outro como um construto inacabado, múltiplo.

ABSTRACT: The purpose of this article is to discuss the discursive strategies used to build unknow identity of Marieta in Marieta e Ferdinando, written by Sérgio Sant'Anna. The work investigates the relations between gender performances and the narrator's project that attempts to represent the other as an unfinished and multiple construct.

PALAVRAS-CHAVE: Fragmentação; Paródia de gênero; Representação; Alteridade KEYWORDS: Fragmentation; Gender parody, Representation, Alterity

Embalados pelas batidas da meia-noite de um relógio qualquer, um casal qualquer, em uma periferia qualquer, no interior de um conto, se desveste de seus papéis de gênero para encenar, diante do leitor, o embate de corpos que não se querem "naturais", de identidades que não se fixam, de existências que escorrem por entre os dedos, fugidias.

Fragmentação, paródia, representação, alteridade são palavraschave para pensar o conto "Marieta e Ferdinando", de Sérgio Sant'Anna. O narrador do conto, em seu projeto de desvelar como o casal incorpora e subverte relações misóginas, expõe as práticas generificadas que delineiam experiências cotidianas distintas a cada um dos cônjuges.

Sob esse imaginário perscrutado do urbano periférico, o narrador de Sérgio Sant'Anna delineia um cenário que possibilita a discussão de

\footnotetext{
1 Ludimila Moreira Menezes é mestranda no Departamento de Teoria Literária e Literaturas da Universidade de Brasília (UnB).
} 
como personagens aparentemente cooptados por uma heteronormatividade escapam desta matriz de comportamentos. Assim a temporalidade ganha contorno significativo no conto ao demarcar as atuações de Marieta e seu companheiro em momentos do dia, como também às doze badaladas do relógio, arauto das transformações identitárias, que anunciam a possibilidade tão excitante do outro na narrativa.

Instauram-se, então, na estrutura narrativa tensões a partir das expectativas e dos investimentos sociais dos corpos, que ficam explícitas no roteiro de atividades femininas empreitadas por Marieta e seus desdobramentos existenciais como a angústia, a ironia ou a paródia.

O narrador, ao problematizar o próprio processo de representação dos personagens, estaria pensando as performances de gênero como ficções sociais? Se o discurso é uma prática que constrói os objetos dos quais se fala, essa autonomia e acuidade do narrador em deslindar os mecanismos de sujeição e controle do corpo, seja no casamento, nas atribuições e afazeres dos personagens ilustraria um engajamento, um fazer literário queer? Adiante voltaremos a isto.

O objetivo deste artigo é analisar a jornada sociocorporal de Marieta, uma das protagonistas do conto e discutir as estratégias discursivas usadas para a construção de sua identidade fugidia. Para tal empreitada cabe analisar a noção de paródia em Judith Butler, que além de problematizar a ilusão de um núcleo interno organizador de gênero contradiz a ideia de origem que perde o sentido e abre espaço para as múltiplas experiências de gênero que se constroem:

Esse deslocamento perpétuo constitui uma fluidez de identidades que sugere uma abertura à re-significação e à recontextualização; a proliferação parodística priva a cultura hegemônica e seus críticos da reivindicação de identidades de gênero naturalizadas ou essencializadas. (BUTLER, 2003, p.197) 
A constituição da personagem Marieta na narrativa demonstra os sentidos possiveis da memória discursiva ${ }^{2}$, pois a personagem é ao mesmo tempo falante e falada, porque através de Marieta outros ditos se dizem como a misoginia, a heterossexualidade, os deslocamentos:

Marieta vem para o quarto e repara que Ferdinando está lendo outra vez. Não adiantou nada ela colocar o vestido bacana e fazer o cabelo e perfumar-se. Ferdinando não prestou a menor atenção. [...] O que existe, agora, é acomodação e indiferença. Eles dois - Marieta e Ferdinando - que juraram amor eterno, não diante de um juiz porque não são verdadeiramente casados. Mas juraram amor eterno e também um outro pacto, que tem sido respeitado. (SANT'ANNA, 1997, p.114)

Verifica-se no texto de Sant'Anna que os personagens refletem o foco do narrador ao indivíduo, que assume a perspectiva de um outro variado, e não de personagens submetidos ao monopólio uniformizador da definição de identidade. Ella Shohat e Robert Stam expressam como a batalha da representação e sua construção estratégica no imaginário social, refletem uma versão mediada de um mundo sócio-ideológico que já é texto e discurso. Sob essa perspectiva os autores expõem que:

Não basta dizer que a arte implica construção. Temos que perguntar: construção para quem? E em conjunção com quais ideologias e discursos? Dessa perspectiva, a arte é uma representação não tanto em um sentido mimético, mas político, uma delegação de vozes. (SHOHAT e STAM, 2006, p.265)

A narrativa que se constrói sobre Marieta, não pretende esgotá-la, nem ocultar as ressignificações do seu gênero. Mesmo casada, inscrita em um sistema misógino de relações de forças, percebe-se antes o escopo do narrador em desenvolver uma tessitura discursiva que evidencie os novos posicionamentos do sujeito e a relação provisória, subversiva estabelecida no pacto da meia noite. Dessa forma, as doze

\footnotetext{
2 Eni Orlandi ao explicitar como as condições de produção do discurso e suas circunstâncias de enunciação se inscrevem em contextos sócio-históricos, ideológicos, revela como o interdiscurso se manifesta pelas filiações de sentidos constituídos em outros dizeres: "Ou seja, é o que chamamos memória discursiva: o saber discursivo que torna possivel todo dizer e que retorna sob a forma do préconstruído, o já-dito que está na base do dizivel, sustentando cada tomada da palavra". (2005, p. 31).
} 
badaladas anunciam a contingência, a desestabilização do próprio gênero de Marieta.

O processo constitutivo da personagem Marieta passa por um projeto de construção de si em reinvenção. Observa-se, com isso a proposta do narrador em apresentar brechas a essa cultura de sujeição que prescreve comportamentos, institui normas e modos de subjetivação.

O conto "Marieta e Ferdinando" explora então a (des)conexão entre possibilidades e estereótipos mostrando a representação de personagens marginais em seus deslocamentos, brechas, resistências. A periferia como unidade aparente a ser narrada é fragmentada: corpos e espaços mostram-se multifacetados, Marieta no transcorrer do texto é o avesso colorido do rastro opaco de sua apresentação primeira. A proposta do narrador se distende sob a periferia que vai além dos enquadramentos das metanarrativas midiáticas, literárias, antropológicas revelando ambiguidades como a de Marieta que confunde e escapa de seus leitores.

Marieta então se esconde de possiveis enquadramentos às suas performances. Não sabemos se ela é uma mulher, homem, travesti, transexual. Lançando mão de uma estratégia desconstrutivista, investigando as tensões geradas pelas tecnologias de gênero ${ }^{3} \mathrm{e}$ valorizando as possibilidades de fissura desse imaginário androcêntrico como elemento constituinte da representação inacabada do outro, Sant'Anna visibiliza estereótipos e desconcerta representações hegemônicas.

\footnotetext{
${ }^{3}$ De acordo com a definição de Teresa de Lauretis, o conceito de "tecnologia de gênero" discute como o referencial androcêntrico produz investimentos, técnicas e estratégias discursivas por meio das quais o gênero é construído: "Posso então reescrever minha terceira proposição: a construção do gênero ocorre hoje através das várias tecnologias do gênero (p. ex., o cinema) e discursos institucionais (p. ex., a teoria) com poder de controlar o campo do significado social e assim produzir, promover e 'implantar' representações de gênero". (1994, p.228)
} 
Além do enfoque dado ao ex-cêntrico ${ }^{4}$ na representação e linguagem, a narrativa do autor permite pensar o processo da construção da identidade como algo conflitante e ambíguo. Em uma proposta multifacetada o narrador recusa a tendência de somente mapear os comportamentos sexistas de Ferdinando, os naturalizados de Marieta, dando lugar de fala às brechas desse sistema engendrado, e também ao movimento que Teresa de Lauretis caracteriza como sujeito do feminismo: "É um movimento entre o espaço discursivo (representado) das posições proporcionadas pelos discursos hegemônicos e o space-off, o outro lugar, desses discursos". (LAURETIS, 1994, p.238)

Cabe, ainda, salientar que tal proposta de viabilizar outro entendimento à realidade do casal abre possibilidades que atravessam, inauguram novas maneiras de apreender Marieta na narrativa que não somente àquela de uma Marieta subserviente e um Ferdinando machista.

A representação da feminilidade na personagem Marieta, é percebida como um plano crítico, inacabado do narrador de tracejar suas condições de possibilidades na trama. Dessa forma, este artigo, ao dar visibilidade a personagens de outras representações discursivas, preconizou que a construção de identidades nestas não se limitasse à afirmação de uma representação pressuposta, pelo contrário, foram elencadas narrativas que problematizam, desmontam tanto o sistema sexual binário com seus modelos fornecidos de existência corporal, quanto o gênero como sentido unívoco.

Nesse panorama de encontros orquestrados, Marieta pode não conhecer Teena Brandon5, protagonista do filme Meninos não choram, a

\footnotetext{
${ }^{4}$ Cabe analisar a argumentação de Linda Hutcheon que ao propor a descentralização do pós-moderno, encontra o ex-cêntrico, o off-centro: "A teoria e a prática da arte pós-moderna tem mostrado maneiras de transformar o diferente, o off-centro, no veículo para o despertar da consciência estética e até mesmo politica - talvez o passo primeiro e necessário para qualquer mudança radical". (1991, p. 103)

5 Meninos não choram (Boys don't cry). Direção Kimberly Peirce. Produção: John Hart, Eva Kolodner, Jeff Sharp e Christine Vachon. Roteiro: Kimberly Peirce e Andy Bienan. Estados Unidos: Fox Searchlight Pictures, 1999.
} 
garota de Nebraska que em conflito com esses balizadores essencialistas (sexo/gênero) empreende uma desconstrução ao sexo inscrito por normas sociais em seu corpo, ou possivelmente não ouviu falar do artista plástico dinamarquês Einar Wegener ${ }^{6}$ que depois de uma cirurgia em 1931 se torna Lili Elbe, e vira personagem do livro $A$ moça de Copenhague, de David Ebershoft ${ }^{7}$, ou talvez em sua última ida ao cinema tenha perdido a sessão de $M a ́$ educação ${ }^{8}$ e não tenha conhecido a drag-queen Zahara, personagem fictícia almodovariana. Entretanto, todas as personagens, inclusive Marieta, experimentaram a produção discursiva das diferenças a partir do que Butler chama de metafísica da substância, ao analisar o sexo como pré-discursivo e instaurador de prescrições que performatizam comportamentos sociais. (BUTLER, 2003, p. 29)

Outro foco analítico de Sérgio Sant'Anna incide sobre o casamento e as matrizes de sentido que perpassam o contrato sexual de Marieta e Ferdinando (autoridade de Ferdinando, silenciamento das vontades de Marieta), discutindo as relações de poder que presidem sua hierarquização. Nesse sentido, o autor visibiliza que as perspectivas individuais de Marieta quase sempre dão lugar ao roteiro e rotina do personagem Ferdinando. Ora se são casados, Marieta o espera com o vestido mais bonito, ele dentre outros afazeres tem como hábito beber no botequim depois dos bicos vespertinos.

Essa cena também coloca a questão da diferença sexual como uma diferença política e, conforme delineia Carole Pateman, esta é a diferença entre liberdade e sujeição: "Na teoria do contrato, a liberdade universal é sempre uma hipótese, uma história, uma ficção política. O

\footnotetext{
${ }^{6}$ Einar Wegener ("Lili Elbe"), artista plástico dinamarquês que decide em 1930 realizar uma cirurgia de transgenitalização. Para maiores informações ver: CASTEL, P. La métamorphose impensable. Essai sur le transsexualisme et l'identité personnelle. Paris: Galimard, 2003.

7 Ebershoff, David. A moça de Copenhague. Rio de Janeiro: Rocco, 2002.

8 Má educação (La mala educación). Direção: Pedro Almodóvar. Produção: Pedro Almodóvar e Agustín Almodóvar. Roteiro: Pedro Almodóvar. Espanha: Sony Pictures Classics / 20th Century Fox , 2004.
} 
contrato sempre dá origem a direitos politicos sob a forma de relações de dominação e subordinação". (PATEMAN, 1993, p. 24)

Como contraponto desta situação traz-se outra cena no intento de ilustrar a brecha, o efeito de resistência apresentado pela personagem Marieta que além do jogo subversivo à meia-noite, parece em determinado momento da narrativa se opor ao roteiro de identidade:

As lágrimas secaram nos olhos de Marieta e, mesmo concentrando-se, apertando os olhos o mais que pode, ela não consegue produzir outras lágrimas. Então Marieta não resiste ao impulso de fazer uma careta. Botar a língua para si no espelho, pensando: "Que idiota você é". E Marieta faz uma porção de caretas. Como se tivesse ficado louca de repente. (SANT'ANNA, p.112)

O conto "Marieta e Ferdinando", ao apresentar ações que apontam para possiveis fissuras deste modelo hegemônico de representações, promove o diálogo, a absorção de fronteiras identitárias, ressignificando o feminino e o masculino, entendendo as múltiplas configurações de gênero como uma construção contingente de sentido.

A questão do espaço marginal emerge como mais um artificio que Sant'Anna utiliza em seu conto, para ilustrar "o território de gente como eles", como um entre-lugar plural em suas manifestações, arranjos sociais, arquitetônicos. Sob esse prisma, Linda Hutcheon discute a questão do Ex-Cêntrico e da descentralização do sujeito como práticas do pós-modernismo na literatura, filosofia, história, argumentando que:

O centro pode não permanecer, mas ainda é uma atraente ficção de ordem e unidade que a arte e a teoria pós-modernas continuam a explorar e subverter. Essa ficção assume muitas formas nas intuições de cultura e, em muitas delas, suas limitações estão passando a ser o foco de atenção. (HUTCHEON, 1991, p. 88)

O espaço recortado, o apartamento, a partir do qual se desenha o conhecimento acerca de Marieta e da própria representação dos personagens, é compreendido como um desdobramento do universo periférico, pelo qual estão circundados. É nessa tessitura social que 
Marieta incorpora e por vezes desconstrói as pedagogias de gênero que circulam em regimes de verdades na sociedade.

Uma interrogação poderia ser assim formulada: quais são os limites da narrativa que apresenta brechas a esse roteiro de identidades evidentes e não rupturas que poderiam sugerir outras possibilidades, não só na hora do pacto como também às claras, na hora da compra do pão, da ida ao botequim. Tal questão é significativa para um projeto de narrador, que acreditamos ser fragmentado e não totalizador de problemas e soluções.

Nessa perspectiva, além das brechas, resistências, verifica-se no conto um arsenal crítico de construções que ironizam a noção de sexo como ideal normativo, que faz parte da prática regulatória que produz os corpos que governa. (BUTLER, 1999, p. 153). Assim, se visibiliza a narrativa:

Ferdinando, agora, tirou os sapatos e jogou-os longe. Os homens são grosseiros, Marieta pensa, enquanto leva os sapatos de Ferdinando para o quarto e os guarda, cuidadosamente, no armário [...] E Marieta pensa que os homens são uns brutos. (SANT'ANNA, p.112)

Cabe mencionar a assertiva do historiador Roger Chartier para compreender o projeto do ficcionista Sérgio Sant'Anna e seu narrador:

Nem todas as fissuras que corroem as formas de dominação masculina tomam a forma de dilacerações espetaculares, nem se exprimem sempre pela irrupção singular de um discurso de recusa ou de rejeição. Elas nascem com frequência no interior do próprio consentimento, quando a incorporação da linguagem da dominação se encontra reempregada para marcar uma resistência. (CHARTIER, 1995, p.42)

Outra problematização ganha destaque no mosaico analítico empreendido pelo narrador acerca do comportamento da personagem. Agora é o construto binário jovem/velha que promoverá uma inquietação em Marieta e uma espécie de denúncia do narrador ao dispositivo estético: "Marieta continua se olhando no espelho e agora se 
concentra em sua pele. A pele que vai se tornando empapuçada no rosto, flácida nos braços no corpo inteiro". (SANT'ANNA, p.112)

Ao entender a velhice como uma categoria social, Tânia Navarro Swain avança em situá-la como componente de uma representação binária, polarizada da velhice/ruim em contraste com a juventude/boa atentando para a criação dos corpos em bases identitárias como o gênero e a idade:

A idade cronológica avança inexoravelmente para todos. Apenas os mortos não envelhecem. Mas o que faz de um ser humano uma pessoa jovem ou velha? Seria o corpo que fenece? seria a memória que escapa, a pele que perde o viço, a carne, cuja firmeza se vai aos poucos? O corpo, é verdade, se estiola; mas a velhice, esta é apenas uma categoria social, criada para melhor separar o humano em hierarquias e impor modelos de consumo e de vida. Aqueles que respondem às necessidades de mercado, ao patriarcado, ao desejo de poder, esta tormenta que assola as relações humanas. (NAVARRO-SWAIN, 2003)

Partindo da proposição de Butler sobre a paródia9, em "Marieta e Ferdinando", somos remetidos, a todo o momento, a uma complexa relação entre normatividade e subversão das categorias identitárias, não sendo esta última apenas a rearticulação simbólica da primeira, mas uma performance de gênero; ou melhor, o gênero como um projeto que nunca está terminado assume as múltiplas condições contingentes de configuração. Dessa forma o projeto do narrador ao reconhecer o ser mulher e homem como ilusão, construção, abre espaço para a paródia, que deixa explícita a existência de uma norma que propositalmente está sendo imitada.

Pensar o cenário discursivo de constituição do acontecimento: "Quando o relógio de parede começa a bater as doze badaladas" (SANT'ANNA, p.114) pelo viés do narrador com o olhar que busca questionar tanto o seu lugar como dos personagens na representação da realidade, permite entendê-lo como uma trama complexa de onde

\footnotetext{
${ }^{9}$ A noção de paródia revela a possibilidade de reformular significados considerados originais atribuídos aos gêneros: "Os gêneros não podem ser verdadeiros nem falsos, reais nem aparentes, originais nem derivados. Como portadores criveis desses atributos, contudo, eles também podem se tornar completa e radicalmente incriveis". (BUTLER, 2003, p.201)
} 
emergem jogos de representação. No entanto não se devem confundir esses jogos de representação como origens dos sistemas de formações dos discursos:

Esses sistemas de formação não devem ser tomados como blocos de imobilidade, formas estáticas que se imporiam do exterior ao discurso e definiriam, de uma vez por todas seus caracteres e possibilidades. [...] Esses sistemas residem no próprio discurso; ou antes em suas fronteiras, nesse limite em que se definem as regras específicas que fazem com que exista como tal. (FOUCAULT, 2004, p. 82)

Sublinha-se aqui um dos momentos mais interessantes do encadeamento narrativo que ilustra o projeto de Sant'Anna de privilegiar hipóteses a fatos certeiros e previsiveis:

Quando o relógio de parede começa a bater as doze badaladas, Marieta retira a peruca e vem depressa para o quarto. Ferdinando põe a revista de lado. E eles se olham - se olham de verdade - pela primeira vez nessa noite. Como se esse momento fosse o único que ainda os excitasse: as doze badaladas da meianoite. Sem a peruca, Marieta não é nem mesmo loura. Seus cabelos são cortados curtos, e negros como os de Ferdinando. Ferdinando e Marieta sorriem uma para o outro e, nesse momento, são gentis e quase idênticos. Se houvesse um terceiro observador no quarto, poderia julgar que os dois são do mesmo sexo, embora dificil precisar qual sexo. E são os dois extremamente parecidos, como esses casais que, com o passar do tempo, vão roubando um do outro simultaneamente, a fisionomia. (SANT'ANNA, p.115)

Em outros contos de Sant'Anna, como: "Na boca do túnel"10, "Um discurso sobre o método"11, "Um conto obscuro"12, os arranjos do urbano também ganham contornos irônicos, perturbadores. A narrativa se afasta do cânone, promove a articulação de paródia, metaficção engendrando a partir de uma escrita multiforme espaços híbridos para seus personagens e para si próprio. Talvez do apartamento de Marieta, seja demorado o percurso até o apartamento do narrador de "Um conto

${ }^{10}$ Conto de Sérgio Sant'Anna presente no livro: Contos e Novelas Reunidos. São Paulo: Companhia das Letras. 1997.

11 Conto de Sérgio Sant'Anna presente no livro: A Senhorita Simpson. São Paulo: Companhia das Letras. 1989.

12 Conto de Sérgio Sant'Anna presente no livro: O vôo da madrugada. São Paulo: Companhia das Letras. 2003. 
obscuro", que ali compõe uma espécie de memorabília, ou quem sabe o operário de "Um discurso sobre o método" possa ter avistado Ferdinando no botequim duas ou três vezes, quando cortava as ruas para chegar a sua casa.

Cabe observar e ganha importância nestes contos a representação do outro que se caracteriza como um construto inacabado a partir da vontade do narrador que além de expor suas idiossincrasias, tem em suas reflexões perpassadas no transcorrer do conto estratégias discursivas que engendram representações possíveis, não definitivas.

Sob esse aspecto, o narrador de "Marieta e Ferdinando" elabora seus enunciados a partir de suas inquietações, percepções daquela marginalidade, e sua narrativa literária como instrumento de comunicação, denuncia como o dispositivo de sexualidade ao supervalorizar a diferenciação dos sexos, cria os corpos e o sexo. (FOUCAULT, 2005)

O narrador de Sant'Anna está no entre-lugar, pois, além de não encarar o discurso e a identidade do outro como seu, o assimila construindo condições fronteiriças para si e para seus personagens. Diante de uma pergunta delineada no início deste artigo, se o narrador estaria engajado em um fazer literário queer, sem pretensões de respondê-la, deixo aqui um rastro incandescente da minha inclinação:

Queer é estranho, raro, esquisito. Queer é, também, o sujeito da sexualidade desviante - homossexuais, bissexuais, transexuais, travestis, drags. É o excêntrico que não deseja ser "integrado" e muito menos "tolerado". Queer é um jeito de pensar e de ser que não aspira o centro nem o quer como referência; um jeito de pensar e de ser que desafia as normas regulatórias da sociedade, que assume o desconforto da ambiguidade, do "entre lugares", do indecidível. Queer é um corpo estranho, que incomoda, perturba, provoca e fascina. (LOURO, 2004, p. 7-8)

Assim "Marieta e Ferdinando" de Sérgio Sant'Anna não é uma narrativa específica, objetiva e pura, é antes uma formação discursiva de produções de sentido sobre um outro a partir das condições dadas, da vontade de poder e do lugar de fala do narrador emprestada aos personagens. Nessa perspectiva, noções como identidades fixas, 
misoginia, contrato sexual, quando confrontadas com a proposta do narrador de Sant'Anna, são parodiadas, ressignificadas e até desconstruídas.

Aqui, não importa uma fotografia verdadeira de Marieta, a personagem é por demais fugidia, como Foucault escrevera outrora: "Não me pergunte quem sou e não me diga para permanecer o mesmo". (FOUCAULT, 2007, p. 20)

Marieta interage com o vir a ser do humano, a reverberação das interações sócio-sexuais da personagem questiona tecnologias de gênero e constitui novas triagens para um sujeito performático.

\section{Referências bibliográficas}

BUTLER, Judith. Problemas de Gênero: feminismo e subversão da identidade. Rio de Janeiro: Civilização Brasileira, 2003. . "Corpos que pesam: sobre os limites discursivos do 'sexo". In: LOURO, Guacira. O corpo educado. Pedagogias da sexualidade. Trad. Tomaz Tadeu da Silva. Belo Horizonte: Autêntica, 1999.

CHARTIER, Roger. "Diferenças entre os sexos e dominação simbólica (nota critica)". Cadernos Pagu, n. 4 (Fazendo história das mulheres), p. $37-47$. 1995.

Disponivel

em:

http://www.pagu.unicamp.br/files/cadpagu/Cad04/pagu04.04.pdf. Acesso em: 05 jun. 2009.

FOUCAULT, Michel. História da Sexualidade I - A vontade de saber. Rio de Janeiro: Graal, 2005.

A Arqueologia do saber. Rio de Janeiro: Forense

Universitária, 2004.

HUTCHEON, Linda. A Poética do Pós-Modernismo. Rio de Janeiro: Imago, 1991.

LAURETIS, Teresa de. "A tecnologia de gênero." In: HOLANDA, H. B de (org) Tendências e impasses: o feminismo como crítica da cultura. Rio de Janeiro: Rocco, 1994. 
LOURO, Guacira Lopes. Um corpo estranho: ensaios sobre sexualidade e teoria queer. Belo Horizonte: Autêntica, 2004.

NAVARRO-SWAIN, Tânia. "Velha? Eu? Autoretrato de uma feminista." In: Labrys: Estudos Feministas, n. 4, agosto/dezembro.2003. Disponivel em: http://www.unb.br/ih/ his/gefem. Acesso em: 02 jun. 2009.

ORLANDI, Eni Pulcinelli. Análise do discurso: princípios $e$ procedimentos. São Paulo: Pontes, 2005.

PATEMAN, Carole. O contrato sexual. Rio de Janeiro: Paz e Terra, 1993.

SANT'ANNA, Sérgio. "Marieta e Ferdinando" In: Notas de Manfredo Rangel, repórter (a respeito de Kramer). Rio de Janeiro: Civilização Brasileira, 1997.

. "Na boca do túnel" In: Contos e novelas reunidos.

São Paulo: Companhia das Letras, 1997. . "Um discurso sobre o método" In: A senhorita Simpson. São Paulo: Companhia das Letras, 1989.

. "Um conto obscuro" In: O vôo da madrugada. São

Paulo: Companhia das Letras, 2003.

SHOHAT, Ella; STAM, Robert. Crítica da imagem eurocêntrica. São Paulo: CosacNaify, 2006. 